Democratizar la comunicación: contingencia y necesidad

Cecilia Beatriz Díaz

Tram[p]as de la comunicación y la cultura (N. $\left.{ }^{\circ} 86\right)$, e047, 2021

ISSN 2314-274X | https://doi.org/10.24215/2314274xe047

http://perio.unlp.edu.ar/ojs/index.php/trampas

FPyCS | Universidad Nacional de La Plata

La Plata | Buenos Aires | Argentina

\title{
DEMOCRATIZAR LA COMUNICACIÓN: CONTINGENCIA Y NECESIDAD
}

THE DEMOCRATISATION OF COMMUNICATION: POSSIBILITY AND NECESSITY

\author{
Cecilia Beatriz Diaz \\ diaz.ceciliab@gmail.com \\ https://orcid.org/0000-0002-1039-2656
}

\section{Departamento de Humanidades y Ciencias Sociales \\ Universidad Nacional de La Matanza | Argentina}

\begin{abstract}
Resumen
Abstract

A partir de la concepción performativa del

Since the performative idea of language lenguaje y de la retórica como ontología and the rhetoric as the ontology of de lo social, se indaga en el proceso de democratización de la comunicación que tuvo lugar en la Argentina (2007-2015) desde la dimensión discursiva de las politicas públicas. Dentro de los estudios sobre la democracia radical, en la que se ubican las experiencias nacional populares latinoamericanas del siglo XXI, se profundiza un aspecto teórico sobre populismo: la tensión entre la lógica de la contingencia social y la lógica de la necesidad histórica. society, it's investigated as an object of study the process of democratization of communication in Argentina (20072015) from the discursive dimension of public communication policies. As a dimension of radical democracy, in which Latin American national popular experiences of XXI century are placed, this paper aims at deepen a theorical aspect about populism: the tension between the social possibility logic and the historical necessity logic.
\end{abstract}

Palabras clave | populismo, democratización, comunicación, discurso, políticas públicas Keywords | populism, democratization, communication, discourse, public policies 


\title{
DEMOCRATIZAR LA COMUNICACIÓN: \\ CONTINGENCIA Y NECESIDAD
}

\author{
Por Cecilia Beatriz Diaz
}

\section{Introducción}

A partir de los aportes de la teoría de Ernesto Laclau con respecto al posmarxismo, la reconceptualización de la hegemonía, la radicalización democrática y el populismo, este trabajo $^{1}$ busca complementar el análisis realizado sobre el proceso de democratización de la comunicación que llevó adelante el kirchnerismo entre 2007 y $2015^{2}$ a través del juego entre las lógicas de la contingencia de lo social y de la necesidad histórica.

Estos conceptos remiten a la deconstrucción del marxismo que Laclau y Chantal Mouffe (1985) postulan a los fines de elaborar una propuesta de acción y de pensamiento para la izquierda, ante el triunfo del neoliberalismo en Europa. De este modo, explican la persistencia de la tensión entre la lógica de la necesidad histórica, por la cual el capitalismo en su desarrollo deviene en un proceso revolucionario y, finalmente, se cierra en el comunismo, y las evidencias históricas que dan cuenta de los escenarios contingentes donde los agentes sociales no son determinados por la teoría. En consecuencia, las lógicas operan en un doble vacío como un dualismo que reduce el análisis y las acciones politicas. 
Para sustentar esa digresión, se toma el caso del populismo kirchnerista que enunció "la democratización de la comunicación" como una disputa clave para alcanzar nuevas emancipaciones de las demandas democráticas. Este proceso se inicia en 2009, a partir de la convocatoria a debatir ${ }^{3}$ sobre el proyecto de la Ley de Servicios de Comunicación Audiovisual (LSCA) que realizara la presidenta de la Nación, Cristina Fernández de Kirchner. En sus periodos consecutivos de gobierno (2007-2011 y 2011-2015), se impulsaron más de cincuenta iniciativas sobre políticas públicas para el sector, lo que da cuenta de la relevancia que tenía para el kirchnerismo la democratización de la palabra.

Sin embargo, con la derrota electoral del Frente para la Victoria (FPV) frente a una alianza conservadora entre Propuesta Republicana (Pro) y la Unión Cívica Radical (UCR) -junto con el apoyo de los principales conglomerados mediáticos- se evidenció que la democratización de la comunicación no se había concretado debido al sostenimiento de los amparos judiciales presentados por las corporaciones de medios sobre el nuevo marco regulatorio de la LSCA (2009), sumado a que el andamiaje burocrático no acompañó el devenir democratizador. Tampoco los niveles de audiencia de los nuevos canales públicos mostraban la apropiación de esos contenidos tendientes a brindar diversidad informativa y cultural (Diaz, 2018). En ese escenario, las políticas del kirchnerismo fueron derogadas, abandonadas o vaciadas de sentido, sin mayores resistencias populares.

En la investigación doctoral (Díaz, 2018), se analizó la construcción de sentido en las políticas públicas de comunicación (PPC), entendidas como discursos estructurados enunciados por el Estado que encarnan una relación de significación social y que tienen la capacidad de configurar horizontes de demanda al institucionalizar sentidos como producto de la disputa política. En ese discurso, el rol que cumple el Estado como enunciador se vuelve central al establecer los límites de lo pensable, que se vuelven concretos en el marco social, jurídico y represivo. Es decir, la dimensión discursiva de la política pública es lo que nos indica qué tan lejos puede llegar la demanda democrática.

El concepto de "democratización de la comunicación" no tiene una definición originaria, es una construcción de los organismos internacionales de derechos humanos que lo señalan como una dirección que deben asumir los Estados. En efecto, se trata de un conjunto de medidas aconsejables que, claramente, 
no es siempre similar ni alcanzable en todos los contextos. Ahora bien, ¿qué ocurre cuando es el Estado el que enuncia la necesidad de democratizar la comunicación? De algún modo, se evidencia que no es democrático, en tanto que asume un devenir que no tiene un fin en la lucha por la libertad y la igualdad, y al tomar a la comunicación, se pone en discusión su distribución como una dimensión del ejercicio del poder al interior de las sociedades democráticas. En el caso argentino, primaron tres sentidos de la democratización de la comunicación: 1) la lucha de lo público para la desmonopolización; 2) la etapa del devenir histórico que impone la demanda de un ejercicio pleno del derecho a la comunicación en su dimensión social; y 3) la universalización de las condiciones de acceso a la información, tecnología y servicios de la comunicación.

Este trabajo, en tanto continuación de la tesis doctoral, se orienta a profundizar la tensión entre la lógica de la contingencia y la lógica de la necesidad como una dimensión de la democracia radical en la que se ubican las experiencias nacional-populares latinoamericanas de siglo XXI. El objetivo general es analizar el proceso de democratización de la comunicación impulsado por el kirchnerismo desde el juego de esas lógicas; a partir de distinguirlas, de examinar las instancias de contaminación y de indagar en la construcción de configuraciones identitarias y de representación en los actores de la política y de lo político, respectivamente.

Para Laclau (1990), "afirmar que algo es radicalmente contingente, que su esencia no implica su existencia, es equivalente a decir que las condiciones de existencia de una entidad son exteriores a la misma" (p. 36). En efecto, si pensamos la contingencia de lo social que evidencia la dislocación del orden, como el elemento disruptivo de la radicalización de la democracia, este no puede ser cualquiera, sino que existe algún tipo de necesidad para que surja. Es decir, sin determinismos, se puede pensar el proceso de democratización de la comunicación, impulsado -sobre todo- con la presentación del proyecto de la LSCA, como signado por un «entre" -y no por una "O»- que vincula la contingencia y la necesidad.

De este modo, se busca complejizar desde estas categorias la investigación previa, a fin de aportar un análisis desde la perspectiva teórica de Laclau que permita observar las dinámicas de juego entre las lógicas y, de ese modo, 
tomar distancia de las miradas binarias. En suma, estas reflexiones pretenden contribuir a la comprensión de un periodo histórico de transformación y de debate para el campo de la comunicación en la Argentina y en América Latina.

\section{La democracia radical y las lógicas en juego}

En este apartado se expone, por un lado, la cuestión de la democracia radical $y$, por el otro, el juego de las lógicas en el desarrollo teórico de Laclau, a los efectos de recorrer las principales acepciones de la llamada "democratización de la comunicación".

En primer lugar, resulta necesario definir al periodo en estudio -los mandatos presidenciales de Cristina Fernández de Kirchner- como populismo, en tanto un tipo específico de radicalización de la democracia (Laclau, 2005) que en su formación social tiene al pueblo como sujeto político. El pueblo surge en la relación equivalencial entre la pluralidad de demandas sociales (peticiones no satisfechas) que logran articularse de manera hegemónica.

En efecto, en esa cadena equivalencial de demandas, de significantes o de elementos particulares puede surgir el significante vacio, aquel elemento que se despoja de su particularidad y que asume la representación de la totalidad. Incluso, si ese elemento es disputado por cadenas equivalenciales diferentes Laclau (2005) lo denomina significante flotante, y es sobre él que se ejerce la disputa del sentido.

Desde esta perspectiva, la construcción de un pueblo es imposible sin el funcionamiento de los mecanismos de representación, por lo que hay un vínculo directo entre populismo y democracia. El significante vacío es aquel que logra homogeneizar las heterogeneidades entre las demandas y es reconocido como el líder que representa esa cadena equivalencial. En ese punto, el afecto constituye un lazo que aglutina al liderazgo, al tiempo que delimita la frontera con el antagonista que dicotomiza el espacio social. Ahora bien, no solo el pueblo se identifica con su líder, sino que este el habla en sus términos y asume ese lugar democráticamente otorgado. De esta forma, hay un doble movimiento, un "locus de tensión" de los representados hacia el representante y viceversa (Laclau, 2005, p. 204). 
En suma, la democracia radical -ya sea en su acepción antagonista o agonista- es la que tiende a la democratización, en tanto que la demanda de igualdad se vincula con la libertad o con lo que se denomina emancipaciones (dado que no hay una única que acontece de una vez y para siempre, sino que son contingentes), sin que ello implique una negación de la tradición liberal ni de la deliberativa, sino el impulso en el plano de lo político para interpelar a las instituciones. Esta teoría plantea que ese plano de lo democrático surge en el momento de la contingencia de lo social, es decir, que no hay leyes históricas ni tareas históricamente asignadas a determinados agentes.

Ahora bien, ¿no hay ningún elemento necesario? ¿Puede ser tan librado al azar? Si así fuera, ¿lo democrático no acontecería a cada momento? Al respecto, Laclau (1990) explica:

Lo que encontramos, por el contrario, es siempre una situación limitada y determinada en la que la objetividad se constituye parcialmente y es también parcialmente amenazada; en la que las fronteras entre lo contingente y lo necesario se desplazan constantemente. Y este doble juego de subversión mutua entre lo contingente y lo necesario es un terreno ontológicamente más primario que el de una objetividad pura o una contingencia total $[\ldots]$. Es en este sentido que lo contingente subvierte lo necesario: la contingencia no es el reverso negativo de la necesidad sino el elemento de impureza que deforma e impide la constitución plena de esta última (p. 44).

En efecto, Laclau y Mouffe (1985) distinguen que en la tensión persistente entre la "lógica de la contingencia" y la "lógica de la necesidad" presente en el pensamiento de izquierda radicó una relación clave para la radicalización de la democracia. Es decir, la posibilidad de la reinvención de lo político, donde el sujeto multiplica sus identidades colectivas y las demandas se vuelven el motor de la política. De alli que los autores de Hegemonía y estrategia socialista (1985) postulen el ejercicio "del movimiento de las fronteras que separan a las dos lógicas opuestas" (p. 38). Es decir, la dimensión democrática se evidencia en el momento de la contingencia, que demuestra que el orden, en tanto sistema de diferencias, está dislocado. Sin embargo, hay elementos persistentes de la lógica de la necesidad presentes en ese movimiento, si no se trataría de un acontecimiento -en términos de Jean-François Lyotard (1979)- que llevaría a un relativismo absoluto. 
En cuanto a los juegos de relación entre las lógicas de la contingencia y de la necesidad, Gloria Perelló (2016) explica que la propuesta laclausiana "subvierte la relación interior/exterior, ya que la contingencia atraviesa el ámbito de la necesidad" (p. 153), por lo que no hay ni una dualidad ni un determinismo. Desde un análisis del pensamiento dialéctico, Martín Retamozo (2017) sostiene: "Debemos ubicar la contingencia como constitución ontológica, como condición de la determinación histórica (la historia es el resultado del incesante juego de la contingencia y las determinaciones)" (p. 292), lo que distingue al pensamiento histórico y al político. Es decir, el primero se dedica a indagar las determinaciones de los procesos y el segundo a identificar la potencialidad de los espacios para lo político, y en esa tensión se articulan la politica, las identidades y lo político.

Desde esta perspectiva, los intereses en pugna no responden únicamente a relaciones objetivas, como pueden ser las de producción, sino a la subjetividad en los múltiples planos en los que el sujeto politico se desarrolla. De esa manera, es la lógica equivalencial entre demandas la que une a los grupos, establece representaciones y construye hegemonía.

En esa línea, el modelo de democracia radical le discute a la forma deliberativa la exclusión de colectivos cuyas demandas excedan los derechos reconocidos y las instituciones. Además, el énfasis en la búsqueda de consensos deja de lado la inevitabilidad del conflicto social (Laclau \& Mouffe, 1985; Mouffe, 1999). De este modo, el conflicto es inherente a la sociedad, dado que hay un "otro" que impide la plenitud del "yo" y así la posibilidad de fijar una identidad que exprese una demanda. De allí surge la relación antagónica (amigo/enemigo).

En este escenario, son las luchas democráticas manifiestas en el plano discursivo las que desde lo político se articulan, mediante las lógicas de equivalencia, y solo así pueden conformar una identidad política común entre sujetos democráticos, es decir: construir una ciudadanía democrática.

Cuando se observa el recorrido del concepto de democratización de la comunicación en trabajos referidos a América Latina, se encuentra una coincidencia en identificar la primera década del XXI como el momento de grandes avances en esa línea, aunque en ellos no se indaga sobre el carácter polisémico de la democratización. Desde el reconocimiento de la LSCA (2009) como "un paso sustancial hacia la democratización de las comunicaciones" 
(Baranchuk \& Rodríguez, 2011) hasta antecedentes que encuadran a todas las politicas locales pos LSCA (2009) en una misma concepción a la que reducen a la desmonopolización (Sel, 2013).

En algunos estudios, la democratización de la comunicación es concebida como estrictamente vinculada a una condición del sistema político y solo alcanzable a partir de un acceso igualitario a los bienes materiales y simbólicos (Segura, 2014). Otras acepciones, en cambio, en línea con el informe MacBride (1980), distinguen el acceso a la comunicación como grados de democratización (Torres Molina, 2014).

La discusión sobre la democratización de bienes simbólicos es retomada en términos de acceso y en relación con la calidad (Fernández Lamarra \& Costa de Paula, 2011). Otras reflexiones, en tanto, se vinculan con la perspectiva en derechos humanos y evalúan los sistemas democráticos en función de sus políticas de género, de salud, de migración (Vigliarolo, 2011), frente a las cuales se reconocen avances pero nuevos desafios relativizan el alcance de la democratización y no se aborda la problemática comunicacional como una dimensión del poder democrático.

Este concepto, que relaciona intrínsecamente la democracia y la comunicación, tuvo su correlato en las categorias de análisis sobre los medios, en un contexto de globalización, para influir en políticas públicas locales en forma de negocios bilaterales, directivas regionales y conductas comerciales multilaterales (Freedman, 2006; Mastrini, de Charras \& Fariña, 2010; Oszlak \& O'Donnell, 1976). La escasez de regulación sobre la propiedad de los medios de comunicación en América Latina es un señalamiento que abunda en las producciones académicas. De este modo, se replica la conformación de conglomerados comunicacionales privados que excluye a las universidades nacionales y a las organizaciones comunitarias, tanto en la producción masiva de contenidos como en la propiedad de licencias, lo que llevó al predominio de la comunicación comercial.

Sin embargo, en el siglo XXI Latinoamérica dio un viraje en el signo de sus políticas públicas de comunicación, que se caracterizó por el clima de confrontación con los medios como actores politicos de suma influencia en la opinión pública (Gómez Barragán, 2012; Koschützke \& Gerber, 2011) que tuvieron su origen en la Revolución Bolivariana (Sel, 2009, 2010) como 
construcción de un nuevo paradigma regional (Badillo, Mastrini \& Marenghi, 2012), con antecedentes europeos (Baranchuk, 2011) pero sin ser un proceso homogéneo (Torquato Barros, 2014, 2016).

En sintesis, se encuentran regularidades y dislocaciones de sentido dadas por las acciones puestas en práctica con diferentes resultados y alcances. Esto permite evidenciar que los significantes no son unívocos ni su sentido es inmutable sino que, muy por el contrario, son producto de asociaciones con otros significantes y con los contextos en los cuales se enuncian. Sin embargo, hay una continuidad en las conceptualizaciones donde el principal actor a interpelar es el Estado como encargado y como garante del proceso democratizador, mientras que se teme por esa intervención -sobre las libertades individuales- que nace del propio reconocimiento por parte del Estado de su carácter no democrático.

Esto condujo a postular en la tesis doctoral una definición de la democratización de la comunicación entendida como aquel proceso que surge del reconocimiento del Estado sobre su carácter no democrático frente a su obligación de garantizar a la ciudadanía el ejercicio pleno del derecho a la comunicación, de modo que desarrolla medidas y/o acciones para ampliar las condiciones jurídicas y materiales a los fines de alcanzar su universalización. Esto, a su vez, implica reconocer y actuar sobre las asimetrías entre los actores comunicacionales -tanto los singulares: ciudadanos, ciudadanas, niños, niñas y adolescentes, medios de comunicación, trabajadores; como los colectivos: asociaciones de empresarios, corporaciones, sindicatos, partidos políticos, organizaciones sociales, universidades, etc.-, en un ejercicio crítico continuo y abierto a la participación sobre el contexto, las condiciones de posibilidad y las alternativas de acción.

En efecto, de la conceptualización no se puede inferir qué lógica prima para impulsar un proceso de radicalización. El carácter necesario se encuentra en las desigualdades presentes en el ejercicio pleno del derecho a la comunicación, pero lo contingente es el llamado reconocimiento del Estado en un momento dado. Si ninguna lógica es determinante, ¿cómo es el juego de sus fronteras? Para ello, se propone desarrollar una estrategia metodológica cualitativa a partir del análisis bibliográfico aplicado a un corpus empírico producido en el marco de la tesis doctoral. Este último es el resultado del 
análisis del discurso político y del modelo protoverbal de la política pública sobre las PPC implementadas durante el periodo 2007-2015 y las entrevistas en profundidad a los funcionarios responsables de las mismas.

\section{La democratización de la comunicación en el juego de las lógicas}

A partir de las conclusiones alcanzadas en la investigación doctoral, en este trabajo se analiza el funcionamiento de las lógicas en su especificidad y en el juego de sus fronteras. Tal como se adelantó, se distinguieron tres sentidos políticos para la democratización de la comunicación durante el kirchnerismo: 1) la lucha de lo público para la desmonopolización; 2) la etapa del devenir histórico que impone la demanda de un ejercicio pleno del derecho a la comunicación en su dimensión social; y 3) la universalización de las condiciones de acceso a la información, la tecnología y los servicios de la comunicación.

Con respecto al primer sentido, se articularon las dimensiones desmonopolizadora y benefactora impulsadas por el Estado en una confrontación con las corporaciones mediáticas. De tal modo que las instituciones de la politica se vuelven representativas de lo político como canales de democratización. En particular, el Estado aparece como el agente transformador y representativo del interés público de la comunicación, en tanto bien simbólico clave de la vida democrática, y como dinamizador de la economia. Si bien esto no implica una novedad conceptual -ya que proviene de la jurisprudencia del derecho a la comunicación-, su valor radica en la enunciación gubernamental de un conflicto que atañe a lo público.

En el caso argentino, el ímpetu de la intervención estatal en la mayoría de las PPC analizadas fue una forma de regulación sobre los parámetros de calidad, de precios, de servicio y de infraestructura a los efectos de disputar con el mercado las variables sensibles al ejercicio del derecho a la comunicación. De algún modo, las PPC fueron pensadas como formas de reorientar las lógicas mercantiles ya consolidadas por la posición dominante de determinados conglomerados mediáticos. 
En cuanto al juego de las lógicas, en este punto prima la lógica de la necesidad, en tanto que las PPC analizadas son enunciadas como avances hacia la desmonopolización. En términos de identidad, la figura del antagonista corresponde al Grupo Clarin como parte de una cadena diferencial con otros disvalores $\mathrm{u}$ otros actores tales como las corporaciones, el capital trasnacional, la última Dictadura cívico militar, el neoliberalismo (pensamiento único), la información como mercancía y los monopolios. Lo cierto es que el enemigo del proceso democratizador no se limita a las empresas, alcanza también al poder judicial. Estas figuras del antipueblo son percibidas como agentes de la imposibilidad o de la negación de la acción emancipadora tendiente a alcanzar la distribución democrática de la palabra.

Ante tal dicotomización del espacio de lo social, el "nosotros, el pueblo" es representado por el Estado interventor, regulador y garante del derecho a la comunicación en su perspectiva social. De ese modo, los valores de la diversidad, el pluralismo, el debate y la participación, entre otros, son enarbolados como parte de la dimensión benefactora de la democratización de la comunicación como impulso y como resultado de la desmonopolización del mapa de medios.

Si bien esto puede parecer una especificidad del sector de la comunicación, lo cierto es que es una característica de la concepción del proyecto kirchnerista como un todo, donde las áreas de gobierno se retroalimentan entre sí con cada medida y con cada gestión. ${ }^{4}$

El segundo sentido construido durante los gobiernos de Cristina Fernández de Kirchner, la "democratización de la comunicación", enfatizaba la dimensión del contexto como una instancia del devenir histórico que impone per se la demanda de un ejercicio pleno del derecho a la comunicación en su dimensión social. Tanto en documentos como en entrevistas a ex funcionarios se observa la regularidad de narrar las PPC en el marco de diferentes conflictos que obligan a tomar decisiones. De ese modo, se encuentran narraciones en las que se señalan como causas el conflicto del paro patronal del sector agroexportador en 2008; la interpelación a la Presidenta para impulsar el proyecto de la LSCA, a partir de los "21 puntos por una radiodifusión democrática" (2004); la apuesta por un modelo productivo de desarrollo; y las políticas de memoria y de reparación por los delitos de lesa humanidad. 
Paralelamente, y dada la imbricación de políticas, hay algunas iniciativas que se señalan como fundantes -por ejemplo, la decisión de la norma de televisión digital en clave de integración regional ante el "apagón analógico»y otras que se consideran como parte de un clima de época -especialmente, aquellas que surgen con posterioridad y como consecuencia de la LSCA (2009)-.

Más allá de las interrelaciones entre las políticas analizadas, nos detendremos en dos contextos para tensionar su carácter necesario: el paro patronal del sector agroexportador en 2008, y las políticas de Memoria, Verdad y Justicia ${ }^{5}$ iniciadas en 2003.

El conflicto entre el gobierno y "el campo" se originó a partir del anuncio de la Resolución 125/08 del Ministerio de Economía y Producción que proyectaba retenciones móviles a las exportaciones de granos, cuya alícuota se vinculaba con el comportamiento del precio internacional, al tiempo que distinguía alícuotas de acuerdo a los cultivos para promover alternativas al predominio de la soja. Ante la cercanía de una cosecha que llegaba a cifras récords, la Mesa de Enlace -unión de entidades de productores de diversa escala como la Federación Agraria Argentina (FAA) y la Sociedad Rural Argentina (SRA)adoptó una serie de medidas de fuerza para reclamar por la no aplicación de la mencionada resolución.

El conflicto adquirió presencia en los medios de comunicación mediante la cobertura periodística de las reuniones, el desabastecimiento de productos, los cortes de ruta por más de 90 días, las marchas y los hechos violentos aislados. En efecto, el conflicto "tuvo la particularidad de aglutinar una diversidad de intereses que parecian imposibles de congeniar y sus repercusiones trascendieron las características de un conflicto gremial o sectorial” (Kulfas, 2016, p. 127).

En términos de la lógica predominante, lo que aconteció fue una contingencia del mercado internacional ante la que se asumió una decisión gubernamental. Estrictamente, política. Sus consecuencias en las relaciones del bloque de poder -sector agroexportador, grupos mediáticos y oposición políticafueron, también, contingentes. Su articulación, entonces, en una interpelación democrática hacia la radicalización es producto del liderazgo, como institución populista. 
Respecto a la vinculación de la "democratización de la comunicación" con el pasado reciente argentino se debe a que ante la derogación de las llamadas "leyes del perdón»6 y el posterior impulso de los juicios a los responsables del genocidio perpetrado, se dinamizaron las indagaciones acerca de las complicidades civiles con el gobierno de facto de las Juntas Militares. En ese entramado, se encuentran las estrechas relaciones de los propietarios de los conglomerados de medios de comunicación con el terrorismo de Estado, tanto en la sociedad Papel Prensa como mediante el ocultamiento periodístico de lo que ocurría.

De tal forma se evidencia el viraje en el rol del Estado, que rompió con el paradigma neoliberal de la comunicación (Díaz, 2013), en correspondencia con los compromisos institucionales de adecuación a la jurisprudencia internacional, a los que la Argentina adhiere desde la reforma constitucional de 1994, mediante la inclusión de los tratados de derechos humanos que integran el artículo 75, inciso 22,7 de la Carta Magna.

Sin embargo, ¿se puede decir que las políticas de memoria, verdad y justicia responden solamente a la lógica de necesidad? Dado que no eran parte de las demandas de las mayorias electorales, ¿qué las volvió necesarias? Aquí solo encontramos una respuesta de la lógica de lo contingente: la voluntad política de la figura del líder.

Se entiende, de esta forma, que el juego de las fronteras entre las lógicas de la necesidad y las lógicas de la contingencia no son determinadas a priori, sino a partir de un discurso que logra establecer entre ellas relaciones tendientes a interpelar políticamente y a construir un horizonte emancipador. En el caso de este estudio, la enunciación que articula las dimensiones de la democratización de la comunicación, en tanto significante con otros puntos nodales relativos a otras políticas públicas del periodo kirchnerista, construye una narrativa en la que lo contingente se vuelve necesario para explicar las decisiones de un proyecto nacional.

Así, la LSCA (2009) se enunció como la institucionalización de otro modelo de sociedad frente a la persistencia del neoliberalismo en el pasado reciente y ubicó en el horizonte emancipador a la democracia comunicacional-política, la organización popular y el bien público. Paralelamente, las iniciativas referidas a medidas en comunicación no solo plasmaron estos sentidos sino que se 
enlazaron con las políticas de memoria y de reparación sobre la violación a los derechos humanos durante la última Dictadura cívico militar, con políticas de desarrollo económico y con dimensiones ampliadas del federalismo.

A partir del populismo kirchnerista, se puede observar que no hay elemento, agente o situación "per se" que desencadene un proceso de radicalización democrática. Las llamadas lógicas de la contingencia y de la necesidad se comportan como fuerzas cuyo encauce es producto de una significación dominante e institucionalizada en la palabra del/la líder/esa. Así como la tarea de la hegemonía es limitar las contingencias para sostener el orden, su ruptura exige la lectura contextualizada de las situaciones para encadenar elementos en una dinámica narrativa.

Sin duda, los significantes no son unívocos, en tanto conservan significaciones sociales anteriores que se activan y se resignifican en las asociaciones de lo político. Es decir, las identidades colectivas se configuran en la dinámica de lo político y se articulan en el significante vacío. Estos procesos no pueden predecirse ni se producen en instancias secuenciales, sino que suceden simultáneamente. Esto, que podría señalarse como una "contaminación", no es más que una característica de lo social donde no pueden distinguirse los límites exactos -y puros- entre lo político / la política, lo histórico / lo nuevo, la disrupción / el orden. En suma, la retórica es el espacio donde se construye la relación lógica entre significantes e identidades en el devenir del conflicto social. Una vez más, es una tarea de la política y no de "lo dado".

\section{Palabras finales}

El impulso de este escrito fue repensar el proceso argentino de democratización de la comunicación desde el debate en torno a la determinación de las lógicas de la necesidad y de la contingencia para explicar el desarrollo de lo político. A los efectos de retomar una discusión clave en la propuesta del posmarxismo de Laclau y Mouffe (1985), se abordó el objeto de la tesis doctoral realizada en 2017 desde una dimensión no indagada.

Con respecto al caso del populismo kirchnerista, se considera que la democratización de la comunicación se inserta en una dinámica rupturista con el pasado reciente en múltiples aspectos. Ante todo, como reparación 
de los derechos no reconocidos por el Estado, al tiempo que intenta configurar un modelo comunicacional en línea con el proyecto político, a los fines de forjar una identidad popular que lo legitime.

Estos objetivos politicos se llevan a cabo en simultáneo, por lo que lo necesario y lo contingente se desplazan en un constante "entre", más que en una oposición. Esta operación es producto de la significación social como acción del discurso, que en el caso de los populismos -democracias radicalizadasadquiere centralidad en la retórica del líder. Por ende, no hay "lógicas" en la medida de procesos coherentes en sus causas y fines, sino fuerzas que se vuelven contingentes y/o necesarias en un contexto determinado, a partir de la articulación que se cristalice en el significante vacío. Esta propuesta de interpretación intenta salir de las "leyes de la historia" y profundizar en la línea constructiva y estratégica del devenir de lo político.

El caso del gobierno de Cristina Fernández de Kirchner evidencia que el Estado puede ejecutar políticas públicas benefactoras pero su sentido de disputa en términos simbólicos y culturales con la configuración de la subjetividad sedimentada en la sociedad es producto de la retórica en juego con el contexto. Por tal razón, no es posible secuenciar la democratización de la comunicación a partir de un elemento, un agente o un punto de contradicción, sino de una articulación de significantes con demandas particulares proyectadas hacia un horizonte de emancipación.

En este sentido, el caso abordado pone de manifiesto que aquello que es percibido por los/as funcionarios/as como necesario implica aspectos contingentes en tanto hechos causales, pero sobre todo despliega respuestas que solo son determinadas por la politica en función de los significantes en juego en un momento dado. Es allí donde el liderazgo, la institución populista por antonomasia, le imprime el rasgo necesario / contingente a los elementos de lo politico para integrarlos a un discurso articulador que los resignifica para un fin. 


\section{Referencias}

Badillo, Á., Mastrini, G. y Marenghi, P. (2012). Politiques publiques de communication et gouvernements progressistes en Amérique Latine: quel héritage de la théorie critique? Trabajo presentado en el Congreso de la Association Francophone Pour le Savoir (ACFAS). Salamanca, España: Universidad de Salamanca. Recuperado de https: / / gredos.usal.es / bitstream/handle/10366/115945/badilloy mastriniymarenghi2012.pdf;jsessionid=DD26862F3C4E91E2850E B7EE587AA922?sequence $=1$

Baranchuk, M. (2011). Ley 26.522 de Servicios de Comunicación Audiovisual. Historia, antecedentes europeos y principales articulos. Ciudad Autónoma de Buenos Aires, Argentina: Autoridad Federal de Servicios de Comunicación Audiovisual (AFSCA).

Baranchuk, M. y Rodríguez Usé, J. (2011). Ley 26522. Hacia un nuevo paradigma en comunicación audiovisual. Ciudad Autónoma de Buenos Aires, Argentina: Autoridad Federal de Servicios de Comunicación Audiovisual (AFSCA).

Diaz, C. B. (2013). Encuentro: inicio hacia una comunicación democrática. Tram/p]as de la Comunicación y de la Cultura, (75), 39-44. Recuperado de http: / / www.revistatrampas.com.ar/2013/12/encuentro-inicio-
hacia-una-comunicacion.html Diaz, C. B. (2018). La democratización de la comunicación. Análisis de los sentidos construidos en las politicas públicas de comunicación iniciadas durante los gobiernos de Cristina Fernández de Kirchner (2007-2015) (Tesis de doctorado). Recuperado de http:/ / sedici.unlp.edu.ar/handle/10915/67662 
Fernández Lamarra, N. y Costa de Paula, M. d. F. (2011).

La democratización de la educación superior en América Latina.

Saénz Peña, Argentina: EDUNTREF.

Freedman, D. (2006). Dynamics of power in contemporary media policy-making. Media, Culture and Society, 28(6), 907-923. https://doi.org/ 10.1177\%2F0163443706068923

Gómez Barragán, J. R. (2012). Análisis de la agenda setting de los medios de comunicación: televisivos, impresos y digitales del Ecuador, entre abril y mayo del 2012, caso Diario El Clarín. Loja, Ecuador: Centro Universitario Nueva Loja. Recuperado de https: / / 1library.co/document/lzg9mvqo-analisis-settingcomunicacion-televisivos-impresos-digitales-ecuadorclarin.html?utm_source=search_v3

Koschützke, A. y Gerber, E. C. (2011). Progresismo y Comunicación. Manos a la obra. Ciudad Autónoma de Buenos Aires, Argentina: Fundación Friedrich Ebert.

Kulfas, M. (2016). Los tres kirchnerismos. Una historia de la economía argentina 2003-2015. Ciudad Autónoma de Buenos Aires, Argentina: Siglo XXI.

Laclau, E. (1990). Nuevas reflexiones sobre la revolución de nuestro tiempo. Ciudad Autónoma de Buenos Aires, Argentina: Nueva visión.

Laclau, E. (2005). La razón populista. Ciudad Autónoma de Buenos Aires, Argentina: Fondo de cultura Económica.

Laclau, E. y Mouffe, C. (1985). Hegemonía y estrategia socialista. Hacia una radicalización de la democracia. Madrid, España: Siglo XXI. 
Ley Nacional 22.285 (1980). Ley de Radiodifusión.

Boletín Oficial de la República Argentina. Buenos Aires, 19/09/1980. Recuperado de

http://servicios.infoleg.gob.ar/infolegInternet/verNorma.do?id=1 7694

Ley Nacional 24.430 (1994). Constitución Nacional.

Boletín Oficial de la República Argentina. Buenos Aires, 10/01/1995. Recuperado de

http:/ / servicios.infoleg.gob.ar/infolegInternet/verNorma.do?id=804

Ley Nacional 26.522 (2009). Servicios de Comunicación Audiovisual. Boletín Oficial de la República Argentina. Buenos Aires, 10/10/2009. Recuperado de http://servicios.infoleg.gob.ar/infolegInternet/verNorma.do?id= 158649

Lyotard, J. F. (1979). La condición postmoderna. Barcelona, España: Cátedra.

Mastrini, G., de Charras, D. y Fariña, C. (2010). Nuevas formas de regulación global. En B. Díaz Nosty y J. Fernández Beaumont (Eds.), Comunicación, Convergencia e Integración en América Latina (pp. 31-64). Valencia, España: Amela.

Mouffe, Ch. (1999). El retorno de lo politico. Comunidad, ciudadanía, pluralismo, democracia radical. Barcelona, España: Paidós.

Oszlak, O. y O'Donnell, G. (1976). Estado y políticas estatales en América Latina: hacia una estrategia de investigación. Documento CEDES. G.E. CLACSO, 4. Recuperado de http:/ / repositorio.cedes.org/handle/123456789/3332 
Perelló, G. (2016). Lazos del psicoanálisis lacaniano con la teoría de la hegemonía. Trabajo presentado en el VIII Congreso Internacional de Investigación y Práctica Profesional en Psicología y Décimo Encuentro de Investigadores en Psicología del MERCOSUR. Ciudad Autónoma de Buenos Aires, Argentina: Universidad de Buenos Aires.

Retamozo, M. (2017). Laclau y la dialéctica. Notas sobre un desencuentro con Hegel (y con Marx). Izquierdas, (36), 278-295. http: / /dx.doi.org/10.4067/S0718-50492017000500278

Resolución Ministerial 125 (2008). Nomeclatura Común del Mercosur. Boletín Oficial de la República Argentina.

Buenos Aires, 10/03/2008. Recuperado de http:/ / servicios.infoleg.gob.ar/infolegInternet/verNorma.do?id=1 38567

Segura, M. S. (2014). La sociedad civil y la democratización de las comunicaciones en Latinoamérica. Íconos, (49), 65-80. https:/ / doi.org/10.17141/iconos.49.2014.1272

Sel, S. (2009). La comunicación mediatizada: hegemonias, alternatividades, soberanías. Ciudad Autónoma de Buenos Aires, Argentina: Consejo Latinoamericano de Ciencias Sociales (CLACSO).

Sel, S. (2010). Politicas de comunicación en el capitalismo contemporáneo. América Latina y sus encrucijadas. Ciudad Autónoma de Buenos Aires, Argentina: Consejo Latinoamericano de Ciencias Sociales (CLACSO).

Sel, S. (2013). La democratización comunicacional en Argentina. Avances en políticas públicas y obstáculos económicos, políticos y culturales. En M. Dantas (Coord.) Avances en los procesos de democratización de la comunicación en América Latina (pp. 139-165). Ciudad Autónoma de Buenos Aires, Argentina: Consejo Latinoamericano de Ciencias Sociales (CLACSO). 
Torquato Barros, C. (2014). Democratização da comunicação: discussão teórico-conceitual e análise comparada de ambientes regulatórios para o setor de televisão nos países do Mercosul (Tese de Doutorado em Comunicação). Universidade Federal da Bahia, Brasil.

Torquato Barros, C. (2016). Democratização da comunicação:indicadores comparativos de media policy e a televisão no Mercosul. Chasqui, (130), 347-363. Recuperado de https://revistachasqui.org/index.php/chasqui/article/view/2633/ 2669

Torres Molina, J. (2014). Políticas públicas y democratización de la comunicación. Questión, (41), 65-80. Recuperado de https:/ / perio.unlp.edu.ar/ojs/index.php/question/article/view/2087

Vigliarolo, F. (2011). Análisis y desafios de la democratización hoy. Entre derechos humanos y nuevos escenarios mundiales: I Conferencia Mundial en Derechos Humanos y Democratización. Ciudad Autónoma de Buenos Aires, Argentina: Prometeo.

\section{Notas}

1 Este escrito constituye el trabajo final del Posdoctorado en Comunicación, Medios y Cultura, en su edición 2017-2018, realizado en la Facultad de Periodismo y Comunicación Social de la Universidad Nacional de La Plata.

2 En su tesis doctoral, la autora analizó los sentidos políticos construidos sobre la democratización de la comunicación en las políticas públicas que tuvieron lugar en el periodo 2007-2015. Actualmente, profundiza sobre los estudios del populismo en clave de género en el ámbito universitario y sobre el análisis del discurso político en los medios masivos.

3 En efecto, la "democratización de la comunicación" -o "democratización de la palabra" - fue un enunciado que se correspondía con la demanda de los 21 puntos de la Coalición por una Radiodifusión Democrática (2004), un petitorio producido por una agrupación de trabajadores/as de prensa, académicos/as, organizaciones sociales y dirigentes politicos para reclamar por un marco regulatorio que reemplazara 
el Decreto ley 22.285 de la última Dictadura cívico militar y sus posteriores modificaciones, de acuerdo a los estándares internacionales de libertad de expresión.

4 La metáfora "ecosistema" de políticas públicas, creación de un entrevistado clave en políticas culturales, permite explicar que la mayoría de las iniciativas en estudio surgió de un proceso decisorio que no suele incluir debates sobre la "cuestión socialmente problematizada", sino un sentido de articulación con otras políticas públicas, incluso de otras áreas. Esta figura puede pensarse como un marco que las dinamiza y que, al mismo tiempo, las limita. En ese plano, se pueden distinguir dos grandes centros de este ecosistema: la LSCA (2009) y el plan Argentina Conectada, que concretizaron la dirección de la intervención estatal en la comunicación en un nuevo paradigma sobre el rol del Estado.

5 Modo de denominación de la dirección política que asumió el kirchnerismo sobre la responsabilidad del Estado democrático sobre los delitos de lesa humanidad cometidos por la última Dictadura cívico militar (1976-1983). Memoria y reparación son los pilares de la politica en derechos humanos que, en particular, incluyen la derogación de las llamadas "leyes del perdón", el posterior impulso de los juicios a los responsables del genocidio perpetrado.

6 Durante el gobierno de Ricardo Alfonsin (1983-1989), se aprobaron las leyes de "Punto Final" (1986) y de "Obediencia debida" (1987). La primera establecía un límite temporal para la denuncia de violaciones a los derechos humanos durante la última Dictadura cívico militar; la segunda, absolvía a los militares subordinados por delitos de lesa humanidad.

7 En el inciso 22 del artículo 75, se establece: "Aprobar o desechar tratados concluidos con las demás naciones y con las organizaciones internacionales y los concordatos con la Santa Sede. Los tratados y concordatos tienen jerarquía superior a las leyes.

La Declaración Americana de los Derechos y Deberes del Hombre; la Declaración Universal de Derechos Humanos; la Convención Americana sobre Derechos Humanos; el Pacto Internacional de Derechos Económicos, Sociales y Culturales; el Pacto Internacional de Derechos Civiles y Políticos y su Protocolo Facultativo; la Convención sobre la Prevención y la Sanción del Delito de Genocidio; la Convención Internacional sobre la Eliminación de todas las Formas de Discriminación Racial; la Convención sobre la Eliminación de todas las Formas de Discriminación contra la Mujer; la Convención contra la Tortura y otros Tratos o Penas Crueles, Inhumanos o Degradantes; la Convención sobre los Derechos del Niño; en las condiciones de su vigencia, tienen jerarquía constitucional, no derogan artículo alguno de la primera parte de esta Constitución y deben entenderse complementarios de los derechos 
y garantías por ella reconocidos. Sólo podrán ser denunciados, en su caso, por el Poder Ejecutivo Nacional, previa aprobación de las dos terceras partes de la totalidad de los miembros de cada Cámara.

Los demás tratados y convenciones sobre derechos humanos, luego de ser aprobados por el Congreso, requerirán del voto de las dos terceras partes de la totalidad de los miembros de cada Cámara para gozar de la jerarquía constitucional». 